\title{
ФИЛОСОФСКО-ПРАВОВЫЕ АСПЕКТЫ КОММУНИКАТИВНОЙ КОНЦЕПЦИИ Ю. ХАБЕРМАСА
}

\section{PHILOSOPHICAL AND LEGAL ASPECTS OF Y. HABERMAS' COMMUNICATIVE CONCEPT}

I. Kozlov

Summary: The author considers the philosophical and legal aspects of $\mathrm{Y}$. Habermas' communicative concept in its relation to the actual problems of development of the Russian modern civil society. The article analyzes the theory of deliberative democracy based on discursive agreement on the most important issues of public life in Russia. It is emphasized that the peculiarity of the habermasian concept of consensus is that legal norms are voluntarily accepted by all members of society in the process of open discussion, and the significance of this principle for modern society is analyzed.

Keywords: civil society, deliberative democracy, Habermas, rational discourse, consensus, public.

\section{Ввецение в проблему}

A ктуальность философско-правовых аспектов творческого наследия Ю. Хабермаса обусловливается, прежде всего, тем, что в переходные, кризисные периоды общественного развития наиболее остро ощущается необходимость рационального обоснования правовых основ гражданского единства с учетом общих, групповых и индивидуальных интересов при сохранении плюральности общественной организации и демократического вектора политического развития. Проблема является тем более весомой для современного российского социума, с его парадоксальным сочетанием энергии индивидуалистического самоопределения, новейших практик позиционирования интересов народного большинства, пока лишенных механизмов правового обеспечения, и укорененного в генетической памяти народа стремление к национально-государственной консолидации перед лицом внутренних и внешних политических вызовов. Определена историческими закономерностями и совпадением обстоятельств сегодняшняя ситуация солидарности подавляющей части общества в глобально-конфликтном политическом поле требует не только текущих оперативных решений, но и усиленной теоретической рефлексии над возможностью такого пути преодоления кризиса, который обновит политико-правовую систему и будет способствовать ее подъему на качественно новую ступень развития.

\author{
Козлов Иван Иванович \\ К.ф.н., дочент, Российская академия \\ музыки имени Гнесиных \\ i.kozlov@gnesin-academy.ru
}

Аннотация: Автором в статье рассматриваются философско-правовые аспекты коммуникативной концепции Ю. Хабермаса в ее отношении к актуальным проблемам развития российского современного гражданского общества. Анализируется теория делиберативной демократии, основанная на дискурсивном согласии касательно важнейших вопросов общественной жизни в России. Подчеркивается, что особенность хабермасовского понятия консенсуса состоит в том, что правовые нормы добровольно принимаются всеми членами общества в процессе открытой дискуссии, а также анализируется значение этого принципа для современного социума.

Ключевые слова: гражданское общество, делиберативная демократия, Хабермас, рациональный дискурс, консенсус, общественность.

Также стоит иметь в виду, что отечественное правоведение, на протяжении десятилетий лишено опыта согласования разнородных дискурсов, и по сей день испытывает потребность в усовершенствовании методологических оснований правового познания.

Особую остроту проблема приобретает в связи со сменой политического курса России в сторону азиатского партнерства, невозможным без утверждения ценности права и его углубленного теоретического осмысления. При этом необходимо подчеркнуть, что правовое обеспечение гражданского общества, в его отечественной проекции, пока не получило исчерпывающего освещения.

В то же время, в западной философско-правовой традиции сформирован спектр концепций, которые при условии критического восприятия могут составить основу национальной общественно-правовой идентичности. Важное место среди них занимает коммуникативная правовая теория Ю. Хабермаса, которая обосновывает правовые механизмы «горизонтальных», диалектических взаимосвязей, обеспечивающих общественное единство.

Отталкиваясь от этого, целью данной статьи является исследование философско-правовых аспектов коммуникативной концепции Ю. Хабермаса в отношении к актуальным проблемам развития современного гражданского общества. 
Анализируя уровень изученности вопроса, стоит отметить, что на постсоветском пространстве наследие Хабермаса попадает в поле зрения исследователей только вначале 1990-х гг., изначально освещаясь в философских аспектах и в контексте более широкой проблематики. Первые академические студии творчества философа представлены в сборнике «Проблемы философской герменевтики» (1990) [1, 4-17]. В монографии П.П. Гайденко $[2,438-446]$ осуществлен сравнительный анализ герменевтичних методологий Ю. Хабермаса и Г.-Г. Гадамера, опять же, исключительно в плоскости философского дискурса. В трудах И. Фармана анализируется социокультурное значение коммуникативной парадигмы мыслителя [3]. Правовые проблемы рассматриваются вскользь, в контексте политологической проблематики. Одним из первых на отечественных просторах опытов осмысления этической концепции Хабермаса стал труд О. Ермоленко [4].

C приобретением опыта развития гражданского общества внимание ученых привлекают собственно правовые аспекты учения известного мыслителя. В частности, с позиций либертарного правопонимания политико-правовую теорию Ю. Хабермаса анализирует В.В. Лапаева [5]. Диалогическая основа хабермасовской коммуникативной философии и концепция делиберативной демократии исследуются О.В. Зайцевым [6]. Специально философско-правовым измерениям учение мыслителя, в частности дискурсивной концепции свободы [7] и теории делиберативной демократии [8; 9], посвящены исследования Р.О. Пархоменко. В контексте становление основных философско-правовых парадигм Новейшего времени учения Хабермаса рассматривается С.В. Деникиной [10; 11$]$.

В то же время, в эпицентр научных интересов попадают публикации зарубежных ученых, в которых теоретическое наследие Хабермаса традиционно осмысливается в различных концептуальных проекциях. В частности, оживленные дискуссии разворачиваются вокруг отпечатанной на страницах «Социологических исследований» статьи датского ученого Б. Фливберга «Хабермас и Фуко - теоретики гражданского общества» [12], которая интерпретируется преимущественно с точки зрения адаптации анализируемых теорий к реалиям постсоветского социально-правового пространства [13].

В то же время, стоит отметить, что, несмотря на растущий интерес к творчеству Ю. Хабермаса, значительное количество собственно философско-правовых вопросов и по сей день остается за пределами научного дискурса. Кроме этого, к новым прочтениям наделенной внутренним диалогизмом и интерпретационной открытостью хабермасовской теории побуждают реалии современной правовой действительности, особенно драматичный и к тому же неотрефлексированный опыт последнего периода. Необходимостью определения одного из возможных подходов к данной проблеме определяет цель и структуру данного исследования.

Результаты исследования. Анализ актуальных проблем российского общества позволяет утверждать, что основополагающим задачей отечественного философско-правового дискурса должно стать обоснование таких механизмов политико-правового регулирования, которые бы позволили сохранить гражданское единство и обеспечили отстаивание общенациональных интересов при максимальном учете интересов отдельных групп и членов социума. При этом, учитывая растущий градус насилия в решении социально-политических конфликтов, предметом особого внимания должно стать нахождение нерепрессивных методов стабилизации, которые бы находились в правовом поле и удовлетворяли государственные ожидания современного сообщества. Также стоит учитывать, что ценностными в данном случае является не только программы практической деятельности, но и этико-правовые модели, которые определяют общий аксионормативный вектор общественного развития.

На наш взгляд, именно такая модель создана в учении Ю. Хабермаса, в котором гражданское общество осмысливается как всеобщий консенсус, что возникает в пределах рационального дискурса, в котором каждый из участников, отстаивая собственные интересы, учитывает необходимость их согласования с некоторым общим нормативным образцом.

Неотъемлемым компонентом этого процесса, по мнению ученого, является «рост публичной рефлексии, которая, лимитируя существующие формы господства и институциональные ограничение, освобождает потенциал коммуникативного действия - символически опосредованной интеракции, ориентированной на взаимопонимание. Именно она обеспечивает устранение тех отношений принуждения, которые незаметно встроены в структуры коммуникации» $[10,176]$ и преодоление систематических коммуникативных нарушений.

На более поздних этапах своего творчества, опираясь на идеи аналитической философии, герменевтики, психоанализа и социологии, Хабермас разрабатывает завершенную модель коммуникативной рациональности, одним из центральных понятий которой предстает «общественность» («Offentlichkeit») - социальный квази-субъект, ориентированный на рациональное обсуждение проблем социально-политического и правового бытия. В свою очередь юридическое оформление «общественности» ученый связывает со становлением демократического государства и отделенной от него сферы гражданского общества. Следовательно, стратегической целью философско-правовых исследований Хабермаса 
встает обоснование возможности ненасильственных, не вертикальных способов социального бытия, осмысленного как «универсальное примирение».

Учитывая сегодняшние проблемы российского общества важно также то, что в хабермасовской модели «все основные значения, которые являются составляющими нормативно регулируемых действий, уже имеют моральный критерий. В полной мере он используется лишь в тех случаях, в которых люди обсуждают конфликты или нарушение норм. С достижением социального мира и переходом к нормативных отношений все социальные взаимоотношения приобретают безусловно этического характера. Золотые правила подчинения закону этически необходимы для определение социальных ролей и норм, важных в любом моральном конфликте, именно они обуславливают дополнительные поведенческие ожидания и надлежащую симметрию прав и обязанностей» $[14,231]$.

На наш взгляд, именно такой нормативно-ценностный подход позволяет осмыслить реальность с точки зрения этических идеалов и установить, какими должны быть политика и право.

Особенно актуальным является и то, что многовекторный диалогический дискурс, основан на аргументах, «которые позволяют выявить общепризнанное нормативное в высказываниях» $[15,125]$ и полученная в нем истина интерпретируются философом и как процесс познания, и как формирование познанной социальной реальности. В этом контексте любое нормативно значимое, действительно моральное решение рассматривается как результат использования социальных дискурсивных практик.

Сущностного значения для осмысления новых социополитических реалий приобретает вывод Хабермаса, что рациональность имеет не сущностный характер, в соответствии с которым значимость нормы задается не изменением, трансцендентальным по своей природе сущностным признаком, а характер процедурный, основан на обращении к ресурсам реального жизненного мира.

Именно эта вариабельность нормативного стандарта, согласуемого с обстоятельствами дискурса, приобретает особое значение для современного общества, с его новыми формами народного волеизъявления и отсутствием общественно легитимизированных механизмов их правового оформления.

Акцентируем, что, несмотря на отрицание априорной основы решений коммуникативного консенсуса, Хабермас стремится выявить реализацию через процедуру социального взаимодействия идеи свободы, кото- рая в своем процедурном воплощении предстает, как формальное равенство участников взаимодействия основана на:

1. равенстве шансов на применение коммуникативных речевых актов участниками дискурса;

2. равенстве шансов на тематизацию мнений и критику;

3. свободе самовыражение, предвзятое формирование подавленных комплексов;

4. равенстве шансов на применение регулятивных речевых актов, обеспечивающих взаимность отношений участников дискурса и исключают привилегии - односторонне обязывающие нормы общения.

Именно субстанциональный (трансцендентальный) принцип формального равенства определяет сформулированный Хабермасом основополагающий процедурный принцип дискурсивной этики, согласно которого «...та или иная норма лишь в том случае может претендовать на значимость, если все, кого она касается, как участники практического дискурса достигают (или могли бы достичь) согласия в том, что эта норма имеет силу» $[14,221]$.

Последнее особенно важно для восстановления информационного баланса современного российского общества и установления правообеспеченного диалогического взаимодействия сторон конфликта. Кроме этого, соблюдение данных требований является необходимым условием избегания вышедших в водовороте социальных преобразований угроз неототалитаризма, какой бы привлекательной и на первый взгляд действенноконсолидирующей не казалась его базовая идея.

Утверждение сохраняет справедливость и в сугубо правовой проекции. Не случайно, в осмыслении права коммуникативная теория Ю. Хабермаса отрицает классический монологизм и утверждает необходимость коммуникативного, диалогического процесса правового познания, который соответствует принципам социального и мировоззренческого плюрализма. При этом правопонимания трактуется философом не как тип рефлексии, а как социальная коммуникация, в процессе которой формируется не только понятие права, но и само право как факт социальной жизни.

Таким образом, процесс познания права в теории Хабермаса сочетается с процессом правообразования: идея права не внедряется в социальную практику извне, а формируется и постоянно обновляется в процессе социального дискурса.

Предложенное Хабермасом определения консенсуса создает почву для дальнейших размышлений над проблемой демократической организации общества как 
конституционному гаранту права. По мнению ученого, право является не механизмом, а результатом участия человека в процессе социально-политической коммуникации. Поэтому концепция делиберативной демократии (от фр. délibération - обсуждение) предусматривает замену либералистской модели гражданского общества как сферы хозяйственной взаимодействия индивидов моделью добровольных объединений, образуют центры политических коммуникаций.

Соответственно, одной из задач современной демократизации Хабермас определяет установление нового «раздела власти» между различными источниками интеграции общества. При этом ученый подчеркивает необходимость обеспечения коммуникативного влияния тех социальных институтов, которые он обозначает понятием «общественность», а также на открытости форм совместной жизнедеятельности людей» к экономической и административной общественным подсистемам.

Согласно Хабермасу, интегративная действенность коммуникации, которая осуществляется через влияние автономных образований общественности, должна утвердить себя как противовес системной интеграции, что происходит в монетарных и административно-властных отношений.

Таким образом, политической системе в теории Хабермаса отводится роль гаранта тех начал социального дискурса, которые ученый связывает с понятием коммуникативной рациональности и основанной на ней процедурной справедливости. Также отмечается, что гражданское общество как сфера деятельности общественности требует дополнения со стороны государственной власти как механизма институционализации политических дискурсивных практик. Касательно сферы правообразования речь идет о формализации многоканального дискурса, общественностью, и о его трансформации в политическую плоскость принятие законодательных решений. С позиций данного подхода современное право рассматривается как формируется и эволюционирует в живом диалоге между парламентом и обществом, а правотворческий потенциал парламентской деятельности оценивается по критерию отра- женности в среде парламентских групп неформальных общественных взглядов (в частности откристаллизованные в процессе социальных изломов 2004-го и 2014-го гг.) с другой стороны, важным является также то, что, учитывая возможность деформации коммуникативной компетенции общественности, Хабермас подвергает сомнению правотворческий потенциал социальной практики и подчеркивает необходимость институционализации «способов разумного коллективного формирования воли» $[16,334]$, которая способна способствовать достижению спонтанного «встречного движения форм коммуникации, соответствующие практическому уму» $[16,335]$. При этом критерием разумности коллективной воли определяется неспособность к нанесению «ущерба конкретным целям участников процесса» $[16,336]$.

\section{Выво $\triangle ы$}

Таким образом, сегодня, как и в другие кризисные периоды истории, наблюдаем вступление, казалось бы, классическими теориями нового и неожиданно практического значения. Значительное место среди них занимает коммуникативно-правовая концепция Ю. Хабермаса, в которой понятие гражданского общества получает дискурсивную интерпретацию. Среди наиболее актуальных философско-правовых идей мыслителя выделяем утверждение:

- нравственности общественного дискурса;

- процедурного характера рациональности и вариабельности нормативного стандарта, согласованного с меняющимися условиями дискурса и интересами всех его участников;

- идеи свободы, в своем процедурном воплощении конкретизированной как формальное равенство субъектов взаимодействия;

- коммуникативного, диалогического процесса правового познания; необходимости формализации многоканального дискурса, осуществляемого общественностью, и его трансформации в политическую плоскость принятия законодательных решений;

- обоснование возможности ненасильственных, не вертикальных способов социального бытия, осмысленного как «универсальное примирение».

\section{ЛИТЕРАТУРА}

1. Проблемы философской герменевтики. - М.: АН СРСР, Институт философии, 1990. - 119 с.

2. Гайденко П.П. Прорыв к трансцендентному: Новая онтология XX века. - М.: Республика, 1997. - 495 с.

3. Фарман И.П. Социально-культурные проекты Юргена Хабермаса. - М., 1999. - 244 с.

4. Ермоленко О. Этика ответственности и социальное бытие человека. - К.: Научная мысль, 1994. - 193 с.

5. Лапаева В.В. Политико-правовая концепция Ю. Хабермаса (с позиций либертарного правопонимания). URL: http://www.igpran. ru/public/articles/ Lapaeva.Polit_prav_konc_Xabermasa.pdf (дата обращения: 18.07.2020).

6. Зайцев А.В. Теория делиберативной демократии и диалог государства и гражданского общества // Демократия в России: проблемы и перспективы раз- 
вития. Матер. Всерос. (с межд. уч.) науч.-практ. конф., посв. 80-летию ДГУ, 22-24 сентября 2011г. - Кизляр, 2011. - С. 32-43.

7. Пархоменко Р.Н. Ю. Хабермас о понятии идеи свободы // Политика и Общество, 2013, № 5. - С. 106-110.

8. Пархоменко Р.Н. Теория делиберативной демократии Ю. Хабермаса // Философия и культура, 2012, № 4. - С. 104-107.

9. Пархоменко Р.Н. Ю. Хабермас о современной демократии // Психология и Психотехника., 2013, № 12. - С. 104-107.

10. Деникина 3.Д. Становление основных философско-правовых парадигм новейшего времени: дис... д-ра филос. наук: 09.00.03. - М., 2005. - 439 с.

11. Деникина 3.Д. Неклассическая и постнеклассическая философия права. - М.: ВГНА Минфина России, 2008. - 230 с.

12. Фливберг Б. Хабермас и Фуко - теоретики гражданского общества // Социологические исследования, 2000, №2. - С. 127-136.

13. Калинин И.К. К дискуссии о гражданском обществе // Социологические исследования, 2001, № 4. - С. 112-122.

14. Хабермас Ю. Моральное сознание и коммуникативное действие. - СПб.: Наука, 2000. - 379 с.

15. Хабермас Ю. Структурное изменение публичной сферы: Исследования относительно категории буржуазного общества (Strukturwandel der Öffentlichkeit: Untersuchungen zu einer Kategorie der bürgerlichen Gesellschaft). — М.: Весь Мир, 2016. — 344 c.

16. Хабермас Ю. Политические работы. - М.: Праксис, 2005. - 368 с.

(c) Козлов Иван Иванович (i.kozlov@gnesin-academy.ru).

Журнал «Современная наука: актуальные проблемы теории и практики»

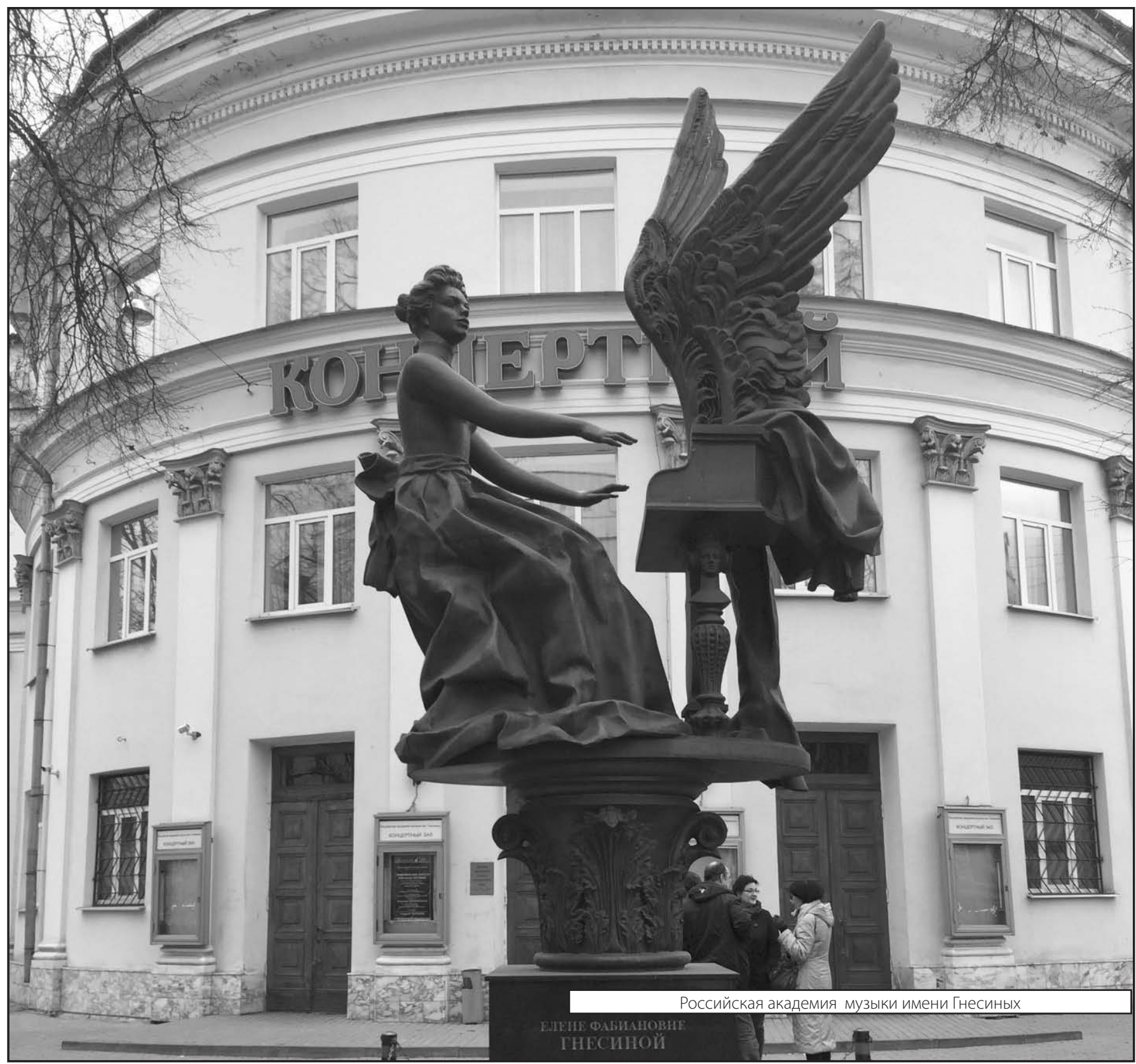

